\title{
SEARCH ME
}

\section{Public opinion on crime and justice in central Johannesburg}

Ted Leggett, Institute for Security Studies ted@iss.co.za

A poll of inner-city residents indicates that many are willing to permit substantial curtailment of civil rights if necessary to make the area safe. 0 ver $\mathbf{8 0 \%}$ of those polled said they would be open to the idea of police searching their homes once a month if this would reduce crime. A third of respondents favoured execution for drug dealers, and $70 \%$ of those who had experienced a police Crackdown operation in their area thought it had helped the situation. This is an expression of the desperation of a community where $88 \%$ of the people do not feel safe walking the streets at night.

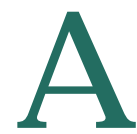
survey of the Johannesburg Central and $\mathrm{Hillbrow}$ police station areas was conducted in mid to late 2002, including a geographic sampling of over 1,300 households, all told. (See SA Crime Q uarterly N o. 2 N ovember 2002.) In addition to detailed questions about criminal victimisation, the respondents were asked their opinions about crime and criminal justice performance in the area. This article is based on their responses.

Most victim surveys ask a set of standard questions about perceptions of safety, and impressions of the state's response to crime. This is opinion data only, more likely to be influenced by yesterday's sensational headlines than a considered analysis of fact. But public opinion is highly important in a capitalist democracy: people vote and invest with their opinions, however uninformed and prejudiced these views might be.

In addition, negative public opinion of the performance of the criminal justice system can lead to very real problems, such as vigilantism, underreporting of crime, and an unwillingness to co-operate with the police as witnesses or informants. These questions also have value simply because they have been asked so many times, and are therefore comparable across jurisdictions and time periods.

Just under half of all the respondents said they had been victims of one of the specified serious crimes in the last year in inner Johannesburg. As a result, much of this data is informed by some direct and recent experience.

A remarkable $61 \%$ of victims claimed to have reported their experience to the police, which reflects a high level of confidence in the authorities overall, but this rate varied sharply by crime type: just over a third of all robberies were reported to the police, for example.

\section{Perceptions of safety}

O ne of the most consistently asked questions in victim surveys is "How safe do you feel walking in the area where you live in the daytime and at night?" The responses to these questions in our survey are graphed in Figures 1 and 2 .

The daytime safety profile is fairly typical for an inner city area, with about half of respondents 
Figure 1: How safe do you feel walking in the area where you live during the day?

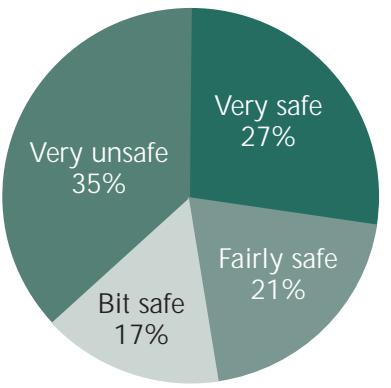

Figure 2: How safe do you feel walking in the area where you live at night?

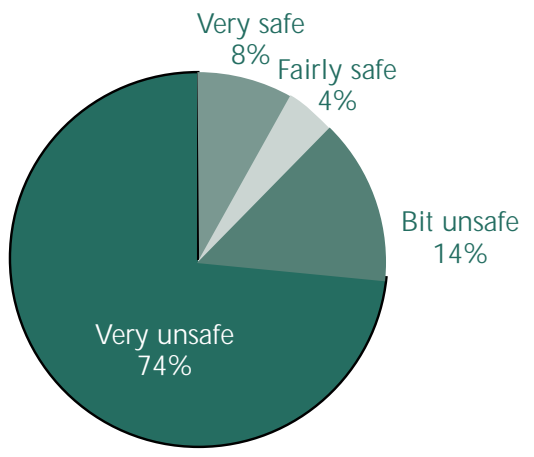

feeling safe and half not. The night time response is, however, quite extreme, with less than $20 \%$ feeling safe on the streets at night, and nearly three quarters feeling very unsafe. Figure 3 compares the answer to this question to similar questions asked in surveys around the world and in South Africa. From this it is clear that feelings of safety at night are lower in inner Johannesburg than in just about any comparable place in the world where similar studies have been done.

However, there was considerable variation within the survey area in this regard. In some areas, upwards of $90 \%$ felt unsafe at night, while in one area, $36 \%$ felt very safe. In the residential hotels, notorious sites for drug dealing and prostitution (See SA Crime Q uarterly N o. 2 N ovember 2002), only $35 \%$ felt safe during the day, and only seven per cent felt safe at night.
Figure 3:

Comparative feelings of night time safety

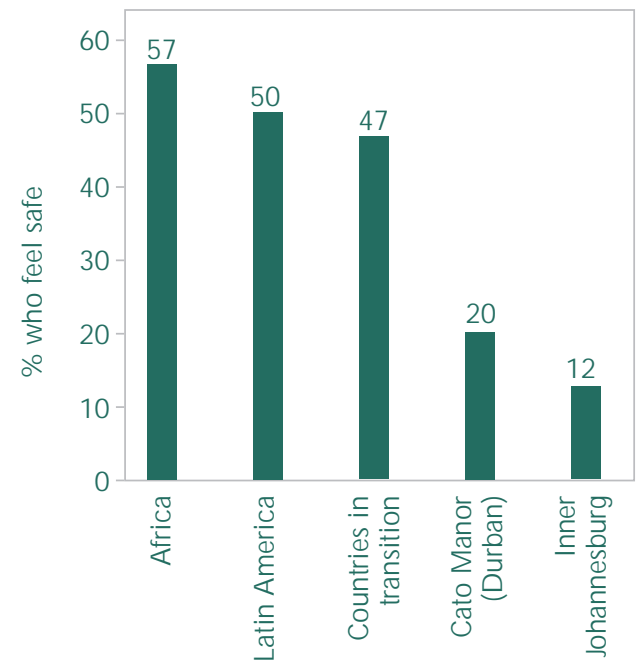

Source: Various sources ${ }^{1}$

Despite this fear, $30 \%$ of the people polled felt that crime in their area had actually decreased since 1994. However, $55 \%$ felt it had increased either a little or a lot, with $15 \%$ saying it had stayed the same. Again, this figure varied quite a bit by survey area: in one area, $67 \%$ felt crime had increased a lot, and in another $40 \%$ thought it had decreased either a little or a lot.

For example, among the majority of Indian respondents from the suburbs south of Johannesburg Central station, there was a feeling that crime had decreased. But these decreases may have been off a very poor base. Almost half of the people who said they thought crime had decreased a lot said they nonetheless felt very unsafe walking at night.

\section{Role of the state}

O verall, $86 \%$ of the people interviewed held government responsible for changes in the crime rate, whether wholly or in part, positive or negative. Of those who thought that crime had increased "a lot" since $1994,87 \%$ felt the government was at least partially responsible for this increase. $0 \mathrm{f}$ those who felt that crime had decreased a lot, $81 \%$ gave the government at least partial credit for this improvement. This suggests that the public believe 
that government possesses the ability to control the crime rate, and that failure to do so represents a lack of service delivery.

As most people living in inner Johannesburg are afraid to walk the city streets, and feel the situation is getting worse, it is not surprising that many favour radical solutions to the problem. The majority of people polled said they favoured the death penalty for murderers, and a third favoured it for drug dealers. White and Indian South Africans in particular favoured the death penalty for both crimes, with southern Africans, central Africans, west Africans, and coloured South Africans being less likely to favour this brutal approach for drug dealers.

Three quarters of the people said they would "definitely" be willing to have their home searched by the police once a month if this would reduce crime, with west, east, and central Africans and whites being less enthusiastic about this prospect. Factoring in those who said they "might" be willing to allow monthly searches, nearly $81 \%$ said they would open their doors to law enforcement, with only $16 \%$ expressing dissent. Surprisingly, in the residential hotels, respondents were slightly more in favour of law enforcement intervention.

These attitudes towards punishment and law enforcement suggest that the residents of inner Johannesburg do not think much of constitutional protections, either for the criminals or, indeed, for themselves. This reflects a sense of desperation in the face of crime that many feel makes the streets unsafe to walk, and against which the state is losing its battle to assert control.

It is not surprising that foreign nationals are less enthusiastic about radical solutions to the crime problem, because if public opinion is anything to go by, they would likely be on the receiving end of these measures. When asked who they think commits most of the crime in their area, $63 \%$ mentioned "foreigners". This is particularly remarkable given that nearly a quarter of the sample was foreign.

In fact, 39\% of foreign nationals said, among other things, that foreigners were responsible for crime.
However, unemployment, a cause particularly favoured by the black community when discussing the causes of crime in other polls², emerged again as the most prevalent explanation: $70 \%$ mentioned unemployed people as the source of crime.

\section{Perceptions of policing}

W ith $70 \%$ of the people interviewed saying that the crime situation had not got better despite government efforts, and most of them blaming government for this lack of progress, it might be expected that public opinion about the police would be poor. But most of the respondents who had been to the local stations said their visit had either improved their opinion of the police (39\%) or that it had stayed the same (36\%). Furthermore, most people felt the local police were doing a good $(20 \%)$ or fair $(41 \%)$ job, with the remaining $38 \%$ feeling they were not doing well.

Those with a negative opinion of the police were most likely to blame this on corruption $(63 \%)$ or laziness (17\%), with very few mentioning racism, brutality, or a lack of resources. In the Johannesburg Central station area, people were less likely to think the police corrupt (58\%), and more likely to think them lazy (20\%), an opinion that may be due in part to the drug trade in Hillbrow.

The vast majority $(77 \%)$ of the respondents said they saw a police member in uniform at least once a day, and $92 \%$ said they knew the location of their local police station. Of these, $62 \%$ had actually been to this station. Most people (84\%) knew to call 10111 if they had an emergency, and only 6\% did not know a number to call. This level of public awareness is truly remarkable, but may be due in part to the high level of population density and crime in the area.

An impressive $22 \%$ knew the name of a police member they could approach with a problem. This single fact is very reassuring with regard to the implementation of community-oriented policing in the area. O ne of the key tenets of communityoriented policing is that police members should establish personal relationships with community members, getting out of their cars and into the neighbourhoods for more contact with the people 
they serve. W hile there is plenty of room to improve this picture, the fact that over a fifth of those polled knew a local cop by name is quite positive.

Hillbrow was one of the areas where the highdensity policing operations conducted under the geographic focus of the National Crime Combating Strategy (popularly known as O peration Crackdown) were premiered. These operations generally involve both police and military personnel conducting building searches, cordon and search operations, and roadblocks, in the most crime-prone station areas in the country. Sixty-one percent said there had been a Crackdown operation in their area in the last two years, and $70 \%$ of these people felt that it had helped to reduce crime in their area. This police policy initiative has apparently caught the public imagination and garnered its support, even in areas as hard hit by operations as Hillbrow.

Residential hotel residents, often the targets of these raids, were not as convinced of their efficacy. Eighty per cent said they knew of an operation in their area, but only $36 \%$ felt that it was worthwhile. This is despite the fact that residents of these hotels were just as likely to say they would allow monthly searches of their homes if this would reduce crime.

U nfortunately, other crime prevention initiatives were not as well-known or popular. Very few people understood the community police forum (CPF) concept. O nly $17 \%$ said they understood what a community police forum was supposed to do. Of these, the most popular response was "to give the police information". O nly $2 \%$ (20 people) said that they knew of a CPF in their area, and of these, only 11 people said they had ever attended a meeting. Five out of the six that regularly attended the meetings said the CPF was working, while those who occasionally or never attended were split three to three on the issue.

This level of awareness falls far short of what the government hopes to achieve with the CPF programme. Every citizen should have access to a $C P F$, yet only $2 \%$ of the inner Johannesburg community was aware that a CPF was operating in their area.
The overall public evaluation of police performance is therefore mixed. The police get top marks for visibility, seem to be doing well in terms of community contact, and are not often accused of brutality and racism. On the other hand, there is a very widespread view that the police are corrupt, especially in Hillbrow. The CPFs do not seem to be widely known, which is a shame given that the poll indicated that the public has a great deal of knowledge about crime in the area. The public seems to prefer, and to be open to, massive raids and searches of the 'Crackdown' variety. The willingness to give up basic privacy rights for some modicum of protection reflects the desperation felt by a community where $88 \%$ of the people do not feel safe walking the streets at night.

\section{Endnotes}

1 For Africa, Latin America, and Countries in Transition, see A Alvazzi del Frate, Victims of crime in the developing world, UNCRI publication number 57. For Cato Manor, see T Leggett, Safe shack living: Criminal vulnerability in shacks and government housing, Nedbank/ISS Crime Index, 5(5), 2001.

2 For example, a victim survey in Durban found that $58 \%$ of black respondents thought job creation was the best non-police solution to making things safer, while less than $35 \%$ of other race groups agreed. See R Robertshaw, A Louw, M Shaw, M Mashiyane, and $S$ Brettell, Reducing crime in Durban: A victim survey and safer city strategy, ISS M onograph series No 58 , Institute for Security Studies, Pretoria, 2001. 